\title{
Oude fragmenten van Jacob van Maerlants Rijmbijbel in handschriften uit het Agnietenklooster te Arnhem ${ }^{(*)}$
}

\author{
Hans KIENHORST \& Mikel KORS
}

In de particuliere collectie van Baron Gebhard von und zur Mühlen (Haus Alvinghof te Senden-Bösensell, Nordrhein-Westfalen) wordt een Middelnederlands handschrift bewaard dat heeft toebehoord aan het Sint-Agnietenklooster te Arnhem. ${ }^{(1)}$ Dit klooster werd rond 1420 als zusterhuis van het Gemene Leven georganiseerd of gereorganiseerd; na verloop van tijd gingen de zusters over tot de Derde Orde van SintFranciscus en in 1459 tot de Reguliere Orde van Sint-Augustinus. ${ }^{(2)}$ Het handschrift was al vóór 1427 eigendom van de zusters, toen ze nog als Zusters van het Gemene Leven tot Her Otten Huus bynnen arnhem woonden, zoals een bezittersnotitie in kolom 156rb van het handschrift uit Bösensell meldt. Later werd bovenaan op de versozijde van het schutblad f. 2 genoteerd Dit boeck hoert den susteren toe bynnen arnhem tot sunte agnieten.

Het handschrift uit Bösensell telt 158 perkamenten folia van ca. $25 \times 18 \mathrm{~cm}$. Het bevat de Middelnederlandse vertaling van Suso's Horologium eternae sapientiae, die begint op f. 3r en eindigt in kolom 156rb. Deze fraaie kopie dateert uit het eerste kwart van de vijftiende eeuw. Zij kan vervaardigd zijn in het klooster van de reguliere koorheren te Windesheim bij Zwolle. ${ }^{(3)}$ Eraan vooraf gaan drie folia, waar-

(*) Dit artikel is het resultaat van onderzoek verricht in het kader van onze aanstelling als postdoc binnen het interfacultaire onderzoekszwaartepunt 'Christelijk Cultureel Erfgoed' van de Radboud Universiteit Nijmegen.

(1) Wir danken Herrn Baron Gebhard von und zur Mühlen, sowie Herrn Von Hopffgarten, dem Bibliothekar, für den freundlichen Empfang und die Einsichtnahme in diese Handschrift. - De officiële naam van de bibliotheek luidt: von und zur Mühlen'sche Bibliothek Nünning, het onderhavige handschrift heeft daar het nummer 20 (olim: Haus Offer sive Ruhr, Bibliothek des Rittmeisters, a.D. Freiherrn Egbert von zur Mühlen, 645,4).

(2) Zie over dit klooster P. Begheyn, 'De handschriften van het Sint-Agnietenklooster te Arnhem', in: $O G E 45$ (1971), p. 3-44, 374-5 (addenda en corrigenda). Over de handschriften die uit dit vrouwenklooster bekend zijn, bereiden wij thans een monografie voor.

(3) Zo is er sterke overeenkomst tussen het penwerk van de initiaal op f. $8 \mathrm{r}$ en het penwerk van een antifonarium dat in 1409 te Windesheim werd vervaardigd. Men vergelijke A.S. Korteweg (red.), 
van het eerste tegen de binnenzijde van het voorplat gelijmd is; ${ }^{(4)}$ achteraan volgen twee perkamenten bladen (f. 157-158). Waar het ons om te doen was, was een blad uit een oud handschrift van Jacob van Maerlants Rijmbijbel, dat als dekblad tegen de binnenzijde van het achterplat gelijmd zou zijn. Bij ons bezoek aan de bibliotheek van Haus Alvinghof bleek dat inmiddels uit de band verwijderd te zijn en in een aparte envelop bewaard te worden. ${ }^{(5)}$

\section{Drie bladen uit hetzelfde handschrift}

De reis naar Bösensell werd gemaakt na een tip van dr. Marinus van den Berg. Bij de voorbereiding van zijn uitgave van het Gaesdonckse traktaten-handschrift (olim Goch-Gaesdonck, Collegium Augustinianum, Ms. 16) ${ }^{(6)}$ stootte hij op (de vermelding van) twee halve bladen uit een Rijmbijbel-handschrift, die daarin als dekbladen zaten. Van den Berg vermoedde een mogelijke overeenkomst tussen deze fragmenten en het bij Stooker en Verbeij genoemde fragment uit Bösensell. ${ }^{(7)}$

Het Gaesdonckse handschrift is een papieren boekje in-octavo met een interessante collectie mystieke teksten van onder anderen Jan van Ruusbroec, Tauler, Gerlach Peters en Suso. Deze codex bleek bij nadere bestudering tussen ca. 1550 en

Kriezels, aubergines en takkenbossen. Randversiering in Noordnederlandse handschriften uit de vijftiende eeuw. Zutphen, 1992, p. 126, nr. 111.

(4) Het gaat hier om een binio, een katern van twee bifolia. Het vierde blad daarvan is weggesneden. De band is van leer over houten platten, versierd met een eenvoudig ruitpatroon van driedubbele blinddruklijnen. Bijzonder aan de band is dat het nog een hulsel van witgelooid leer heeft, overhangend, met uitsparingen voor de twee sloten.

(5) Van dit handschrift bestaat een beschrijving die op 8 oktober 1908 door A. Bömer voor de toenmalige Königliche Preussische Akademie der Wissenschaften werd gemaakt. Deze beschrijving bevindt zich, net als alle andere Akademiebeschreibungen, in het Handschriftenarchiv der Berlin-Brandenburgische Akademie der Wissenschaften zu Berlin, Arbeitsstelle 'Deutsche Texte des Mittelalters' (ca. 19.000 beschrijvingen, deels op internet http://dtm.bbaw.de/HSA/ startseite-handschriftenarchiv.htm te raadplegen, waaronder ook het handschrift Senden-Bösensell, hier i.v. 'Haus Ruhr'). Het Rijmbijbel-fragment was toentertijd nog tegen de binnenzijde van het achterplat vastgelijmd. Volgens Bömer bevond zich voorin het handschrift nog een 'los blad', met op de voorzijde een Middelnederlands gedicht over de vergankelijkheid van het leven. Inc: Ghy lyt altoes ghy en woont hier niet / Een pelgrim sydy en anders niet. Expl: Want ghy maer henen en lydt / ghy en woont hier niet. Dit blad was bij onze autopsie niet meer aanwezig; hiernaar zullen wij nog nader onderzoek doen.

(6) In 2005 verschenen als deel IX in de reeks Middeleeuwse Verzamelhandschriften uit de Nederlanden.

(7) Karl Stooker \& Theo Verbeij, Collecties op orde. Middelnederlandse handschriften uit kloosters en semi-religieuze gemeenschappen in de Nederlanden. $2 \mathrm{dln}$. Leuven, 1997 (= Miscellanea Neerlandica 16), deel 2, p. 56, nr. 149. Wij danken Marinus van den Berg hartelijk voor de gelegenheid die hij ons bood verdere naspeuringen naar het fragment uit Bösensell te doen. 
1570 in het Arnhemse Agnietenklooster vervaardigd te zijn. Eén van de handen kon geïdentificeerd worden als zuster Alberta Thonysdr. van Middachten, die daar tot haar dood in 1570 bewaarster van de boeken was. ${ }^{(8)}$ Aangezien het handschrift uit Bösensell eigendom van hetzelfde klooster was, konden de fragmenten dus goed uit dezelfde Rijmbijbel-codex afkomstig zijn. Het octavo-handschrift bevond zich in 1701 in het klooster van de Augustijner koorheren te Gaesdonck, gezien de contemporaine notitie Gaesdonck 1701 in de buitenmarge van $\mathrm{f} .1 \mathrm{r}$.

Gaesdonck Ms. 16 is in de tweede wereldoorlog verloren gegaan, maar er zijn foto's van bewaard gebleven in de albums 26-28 van de zogenaamde Brandsmacollectie, die zich in het Titus Brandsma Instituut te Nijmegen en het Nederlands Carmelitaans Instituut te Boxmeer bevindt. ${ }^{(9)}$ De eerste foto in album 26 laat een zijde van het fragment zien dat tegen het voorplat gelijmd was. Bovendien beschikken we over een zeer uitgebreide beschrijving, die dr. K. Christ in maart 1910 maakte voor de toenmalige Königliche Preussische Akademie der Wissenschaften in Berlijn. ${ }^{(10)}$ De fragmenten worden door hem als volgt beschreven: ${ }^{(11)}$

Op de binnenzijde van de beide platten waren als dekblad twee perkamenten bladen geplakt, die nu vrijwel geheel losgeraakt zijn, maar nog door de binding in de rug vastgehouden worden. Ze bevatten gedeelten uit Maerlants Rijmbijbel en zijn delen van eenzelfde blad van een verloren codex, dat eerst in tweeën werd gesneden waarvan de helften met de randen der breedste zijden zo werden ingevoegd, dat de regels in de lengterichting van het plat lopen. Door het afsnijden van de gedeeltes die over het plat uitstaken, gingen acht regels $(=\mathrm{ca} .4 \mathrm{~cm}$ ) in het midden van de kolommen verloren. De schriftspiegel van de fragmenten is $13 \mathrm{~cm}$ breed en $9 \mathrm{~cm}$ hoog, tweekoloms met 18 regels. Het oorspronkelijke handschrift had derhalve een schriftspiegel van $22 \times 13 \mathrm{~cm}$, met 44 regels per kolom. De verzen zijn afgezet en beginnen met uitgesprongen en gerubriceerde hoofdletters.

Daarna volgt een volledige transcriptie van de fragmenten, waarbij de verzentelling

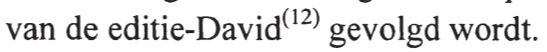

Nadat wij het fragment-Bösensell hadden teruggevonden, kon al direct worden vastgesteld dat het hier om dezelfde kopiist ging als die van de Gaesdonckse

(8) Voor de bewijsvoering zie men de codicologische beschrijving door Hans Kienhorst in de inleiding tot de MVN-uitgave (zie noot 6). Overigens was het Gaesdonckse handschrift ook volgens Stooker \& Verbeij (zie noot 7) , p. 54, eigendom van het Sint-Agnietenklooster te Arnhem, dit in navolging van J.A.A.M. Biemans, Middelnederlandse bijbelhandschriften. Leiden, 1984 (=Verzameling van Middelnederlandse bijbelteksten. Catalogus), p. 243-244, nr. 240.

(9) Vóór 1940 had prof. dr. Titus Brandsma het handschrift laten fotograferen in het kader van zijn Medii aevi manuscriptorum spiritualium neerlandicorum reproductio.

(10) Deze beschrijving is in Berlijn te raadplegen (vergelijk noot 5).

(11) Gemakshalve is de Duitse tekst door ons vertaald.

(12) Jacob van Maerlant, Rijmbijbel. Met voorrede, varianten van handschriften, aenteekeningen en glossarium. Uitgeg. door J. David. 3 dln. Brussel, 1858-1859. 
fragmenten. Het fragment-Bösensell is een (nagenoeg) volledig blad met een hoogte van ruim $24 \mathrm{~cm}$ en een breedte van 17 à $17,5 \mathrm{~cm} .{ }^{(13)}$ Van de ondermarge, die maar 2 $\mathrm{cm}$ is, kan iets zijn afgesneden; de bovenmarge bedraagt 1,4 cm. De schriftspiegel is bijna $21 \mathrm{~cm}$ hoog, wat aardig overeenstemt met de hoogte van de schriftspiegel zoals opgegeven door Christ. Hij had in de telling van het aantal regels per kolom overigens een vergissing gemaakt. Uit vergelijking met de uitgave-David konden wij opmaken dat tussen de bewaard gebleven helften zeven in plaats van acht regels moeten zijn weggesneden, en dat het aantal regels per kolom op de rectozijde 45 en op de versozijde 42 bedroeg. Het blad omvat de verzen 8245-8418 uit genoemde editie.

Bij het blad uit de codex te Bösensell staan daarentegen op de rectozijde 54 regels en op de versozijde 53 regels per kolom. Het schrift is hier ook nog kleiner dan op de gefotografeerde zijde van het fragment voorin de Gaesdonckse codex. Overigens zijn op beide zijden van het blad nog vrij goed de lijnen zichtbaar waarop de verzen geschreven zijn. Van de verticale lijnen resteren slechts enkele vage sporen. Vermoedelijk was voor elk der beide kolommen links een driedubbele lijn en rechts een enkele lijn getrokken; de schrijflijnen lopen over het tussenkolometje door. De afstand tussen de buitenste verticale lijnen bedraagt $14 \mathrm{~cm}$; de binnenmarge is $1 \mathrm{~cm}$, de buitenmarge ruim $2 \mathrm{~cm}$. De tekst van het fragment correspondeert met de verzen 28526-28739 uit de editie-David.

Nadat wij het vermoeden van Van den Berg bevestigd hadden, kwamen wij nog op het spoor van twee helften van een derde blad. De betreffende fragmenten waren in 1879 door J. van Vloten uitgegeven naar een afschrift dat prof. H. Suchier uit Halle hem in het najaar van 1878, vóór zijn vertrek uit Münster, had toegezonden. ${ }^{(14)}$ Uit de editie konden we al min of meer opmaken, dat het waarschijnlijk om een blad uit dezelfde Rijmbijbel-codex ging. Evenals bij de Gaesdonckse fragmenten zaten de twee helften daarvan als dekbladen in een papieren octavo-boekje, en wel een codex uit de toenmalige Paulinische Bibliothek te Münster, maar ook dit handschrift is in de tweede wereldoorlog verloren gegaan. Het bevatte een afschrift van een Middelnederlandse vertaling van Hendrik Herps Eden seu Paradisus contemplativorum, die in 1886 door F. Jostes werd uitgegeven. ${ }^{(15)}$ Het blad was zodanig versneden, dat van elke kolom de bovenste twee regels ontbreken. Het oorspronkelijke aantal regels per kolom bedroeg op beide zijden 47; overgeleverd zijn de verzen 26907-27092 uit de editie-David.

(13) Gemeten is op de afdruk die we van de gefotografeerde rectozijde hebben.

(14) [J.] V[an] VI[oten], 'Fragmenten uit Maerlants Rijmbijbel', in: De Dietsche Warande. N.R., dl. 2 (1879), p. 454-459.

(15) Zie hierover R. Lievens, 'Hendrik Herps Eden in het Middelnederlands', in: Tijdschrift voor Nederlandse taal-en letterkunde 89 (1973), p. 1-11. Een korte beschrijving van het handschrift wordt gegeven in J. Staender, Chirographorum in Regia Bibliotheca Paulina Monasteriensi. Catalogus. Bratislava, 1889, p. 112, nr. $509(=698)$. 
Tot ons geluk bleek zich in de Bibliotheca Neerlandica Manuscripta in de Universiteitsbibliotheek te Leiden een beschrijving van het Münsterse handschrift te bevinden. De Vreese verstrekt daarover de volgende codicologische gegevens:

Papier, $16 \times 10 \mathrm{~cm}, 21$ regels per pagina, $16^{\text {de }}$-eeuwsch schrift, vooraan onvolledig. Oude band met 2 sloten, geheel verweerd. (f. IIIb [latere doorgestreept] andere, cursieve hand) Desen boeck hoort toe die Religieussen int Closter nasaret binen Gelder

De fragmenten waren volgens De Vreese $15,5 \mathrm{~cm}$ breed en ca. $10 \mathrm{~cm}$ hoog. Op een ervan stond $S$ ' fyken van Nerdt. Hier lag een duidelijke link met de Gaesdonckse fragmenten. Op de door Brandsma gefotografeerde zijde staan onder elkaar de namen $S$ ' Anna van Aerdt en S'fyken van Aerdt. De Vreese kan heel wel de $A$ van Aerdt voor een $N$ hebben aangezien. Maar de BNM gaf meer. In zijn beschrijving van de codex uit Bösensell ${ }^{(16)}$ meldt De Vreese dat het fragment uit dat handschrift en de fragmenten uit de Münsterse codex volgens hem uit dezelfde Rijmbijbel-codex afkomstig zijn.

Hoewel het Münsterse handschrift op de versozijde van het derde schutblad het bezittersmerk van het vrouwenklooster Nazareth te Geldern in Nordrhein-Westfalen draagt, moet het dus toch uit het Agnietenklooster te Arnhem stammen. Hiervoor is wellicht een verklaring te geven. Onder andere de handschriften Berlijn, SBPK, mgf 242 en 243, die in het Agnietenklooster te Arnhem werden geschreven, kwamen later terecht in het klooster der reguliere koorheren te Gaesdonck. Op een zeventiende-eeuwse aantekening op het schutblad van mgf 242 wordt een zuster Fyken van Oerdt (mogelijk een dialectvariant van 'Aerdt') genoemd als een van de (laatste overgebleven) zusters uit het Agnietenklooster, die de twee banden in 1644 naar het klooster in Gaesdonck hadden meegenomen. In tegenstelling tot het Gaesdonckse handschrift mist het Münsterse de notitie Gaesdonck 1701; althans De Vreese meldt haar niet. Daaruit zouden we kunnen opmaken dat het zich in dat jaar al niet meer in Gaesdonck bevond.

Het is met andere woorden goed mogelijk, dat de paters uit Gaesdonck, die met de geestelijke leiding van de zusters in Geldern belast waren, het Münsterse handschrift en wellicht andere (Middelnederlandse) handschriften naar dit vrouwenklooster getransporteerd hebben. Dit zou kunnen verklaren waarom het tóch een bezittersmerk uit Geldern draagt. ${ }^{(17)}$ In dit licht bezien zou eigenlijk het omvangrijke

(16) In de map 'Münster, Haus Offer, Freiherr zur Mühlen', beschrijving hs. 645 (thans Bösensell Hs. 20).

(17) Het komt dan ook niet overeen met de middeleeuwse bezittersmerken die Monika Costard noemt in haar bijdrage 'Predigthandschriften der Schwestern vom gemeinsamen Leben. Spätmittelalterliche Predigüberlieferung in der Bibliothek des Klosters Nazareth in Geldern', in: V. Mertens \& H.-J. Schiewer (eds.), Die deutsche Predigt im Mittelalter. Internationales Symposium am Fachbereich Germanistik der Freien Universität Berlin vom 3.-6. Oktober 1989. 
handschriftenbezit uit Geldern in zijn geheel eens opnieuw geëvalueerd dienen te worden.

\section{Datering en lokalisering}

De fragmenten Bösensell (Bö) en Gaesdonck (Ga) zijn geschreven door dezelfde kopiist. Dat geldt vrijwel zeker ook voor Münster (Mü), gezien de opmerking van De Vreese dat Bö en Mü tot dezelfde codex behoren. Hij dateert het handschrift in de eerste helft van de veertiende eeuw. ${ }^{(18)}$ Wij zouden het op grond van een aantal schriftkenmerken nog eerder, in de vroege veertiende eeuw willen plaatsen.

Het schrift is een tamelijk kleine tot zeer kleine littera textualis, geschreven met een niet al te brede pen. Opvallend is de vorm van de minuskel $a$, waarvan de krul vanaf de buik van de letter aan de rug verbonden is. ${ }^{(19)}$ Dat zij ver boven de middenzone uitsteekt, kan te maken hebben met het kleine formaat van dit schrift. Een oud verschijnsel is het nog tamelijk vaak voorkomen van de lange $s$ aan het woordeinde. Waar wel een ronde $s$ staat, is deze vaak even hoog als de rechte vorm. Een ander relatief oud kenmerk is de zogenaamde tong-e, die consequent aan het woordeinde voorkomt; de haal waarmee de 'kop' wordt afgesloten, steekt daarbij ver buiten de letter naar rechts uit.

Opmerkelijk is ook dat de kopiist alleen de rechte $r$ en niet de ronde, 2-vormige $r$ gebruikt; dat de achtvormige $g$ onderaan nog een grote boog heeft, die ver onder de regel uitsteekt, waarbij de diagonale haal die beide bogen verbindt, onderaan naar links uitsteekt; en dat de letter $t$ vaak niet of nauwelijks te onderscheiden is van een $c$, vanwege de ronde vorm van de schacht, die doorgaans niet boven de dekstreep uitsteekt; en waar de ronde $d$ een korte schacht heeft, is verwarring met deze $t$ eveneens mogelijk. Tenslotte zijn de verzen tamelijk breed geschreven, komen rondboogverbindingen niet of nauwelijks voor, en zijn delen van woorden soms uit elkaar getrokken (bv. Ga Rb1 be hoorde en Bö Rb35 vreem den).

De versregels beginnen met een majuskel, met uitzondering van de $a, v$ en $w$. Zoals Christ in zijn beschrijving al opmerkt, staan de beginletters in een apart ko-

Tübingen, 1992, p. 194-222, i.c. 204-206. Ook de taal (hoort, Religieussen) wijst op een veel latere datering.

(18) Middelnederlandsch Woordenboek deel X, Bouwstoffen: Eerste gedeelte (A-F) door W. de Vreese, art. 390.60. Het betreft hier de Münsterse fragmenten. Intrigerend is de opmerking dat het handschrift "waarschijnlijk in het klooster "Nazareth binnen Gelre" verknipt is: ook in andere hss. uit die streek zijn er fragmenten van aanwezig'.

(19) Vgl. B. Engelhart en J.W. Klein, 50 eeuwen schrift. Een inleiding tot de geschiedenis van het schrift. Amsterdam, 1988, p. 98, over een van de twee gebruiksschriftvormen die in de gotische periode uit de laat-Karolingische $a$ ontstaan : 'Hierbij werd de pen, na het maken van de buik, niet van het papier gehaald, zodat de beweging vanaf de buik naar het begin van de krul aan de rug meegeschreven werd'. 
lommetje op enige afstand van de rest van het vers. In Gaesdonck zijn ze elk afzonderlijk met een likje rood gehoogd; in Bösensell is een doorlopende, grove rode streep door de kapitaalkolom getrokken. De initialen zijn eenvoudige rode lombarden, waarvoor (op Bö recto) een drie of (op Bö verso en Ga recto) een vier regels hoge ruimte is uitgespaard, waarin een representant geplaatst werd. De beginletters rechts van deze lombarden hebben de minuskelvorm.

De fragmenten vertonen dus onderling zowel in regeltal als in rubricering verschillen. Een opvallende afwijking in spelling betreft de vorm cam(en) (Bö) tegenover quam(en) (Ga, Mü). ${ }^{(20)}$ Aangezien de fragmenten door dezelfde kopiist geschreven zijn en Bö en $\mathrm{Ga}$ zeker en Mü waarschijnlijk als bindmateriaal voor handschriften uit het Arnhemse Agnietenklooster gebruikt zijn, mogen wij desondanks aannemen dat ze uit hetzelfde handschrift afkomstig zijn. Voor de fragmenten Bö en Mü wordt dit bevestigd door de dialectexpertise van prof. dr. Amand Berteloot (Westfälische Wilhelms-Universität Münster). ${ }^{(21)}$

Berteloot sluit zich aan bij onze indruk dat het dialect van de fragmenten West-Vlaams is. Wij geven hier de relevante passages uit het verslag van zijn expertise : ${ }^{(22)}$

Bij het lezen van de transcripties kreeg ik de indruk dat de Gaesdonckse en de Münsterse fragmenten sterke, indien niet volledige overeenkomst vertonen. Ze zijn zonder enige twijfel uit dezelfde streek afkomstig - wat dus strookt met de identiteit van het schrift. Die streek lijkt me zonder twijfel West-Vlaanderen te zijn. Het gebruik van hem lieden (8293) in plaats van gewoon hem (in het Brusselse handschrift dat door Gysseling is uitgegeven ${ }^{(23)}$ ) en och $=$ woch (8287) naast dieg(h)one binnen in de regel (8339 en 27064) kan erop wijzen dat het wat zuidelijker geplaatst moet worden dan het Brusselse handschrift. ${ }^{(24)}$ De versterking van het persoonlijk voornaamwoord met -lieden heb ik vaker in Frans-Vlaanderen gezien en degunne e.d. zijn vandaag de dag nog voorhanden in het Kortrijkse en werden door Willemyns ${ }^{(25)}$ ook in de late Middeleeuwen in die streek gelokaliseerd. Opvallend is hier wel een sporadische

(20) De enige keer dat Bösensell quam zou kunnen hebben, betreft een nauwelijks leesbare plaats.

(21) Het verschil in spelling van het woord 'kwam(en)' (quam(en) in de berijming van Scolastica t.o. cam(en) in de Wrake van Jherusalem) is volgens Berteloot niet toe te schrijven aan het gebruik van twee leggers.

(22) Mail van 2 juli 2004. Wij danken prof. Berteloot hartelijk voor zijn dialectgeografisch onderzoek van de fragmenten. De noten zijn door ons toegevogd.

(23) Hs. Brussel, Koninklijke Bibliotheek, 15.001. Gedoeld wordt op de uitgave in Maurits Gysseling, Corpus van Middelnederlandse teksten (tot en met het jaar 1300). Reeks II: Literaire handschriften. 6 dln. 's-Gravenhage, Leiden, 1980-1987.

(24) Zie vorige noot. Dit handschrift is Noordwest-Vlaams, uit de streek van Brugge.

(25) Men zie R. Willemyns, Bijdrage tot de studie van de klankleer van het Brugs op het einde van de Middeleeuwen (mit einer deutschen Zusammenfassung). Tongeren, 1971 (= Werken uitgegeven door de Koninklijke Commissie voor Toponymie en Dialectologie, 12), p. 278-82. 
tendens tot vermijding van sommige gewestelijke karakteristieken. De kopiist schrijft b.v. kort achter elkaar beide en beede (8376 en 8378), maar het meest opvallende kenmerk is inderdaad de vermijding van cam(en) ten voordele van quam(en). Om deze reden had ik eerst aan een wat latere datering dan 'het begin van de 14de eeuw' gedacht, maar dergelijke fenomenen zijn zeer moeilijk te dateren (...).

Het stuk uit Bösensell komt wat de taal betreft vrijwel volledig met de andere twee overeen, maar het is in zoverre 'West-Vlaamser' als het cam(en) niet vermijdt. Het viel me ook op dat de kopiist niet alleen $v p$ schrijft (zoals in Gaesdonck/Münster), maar bij gelegenheid ook het moderner aandoende up. De lokalisering kan m.i. niet anders zijn dan bij die van de vorige twee fragmenten. Alleen de behoefte om de typische lokale karakteristieken los te laten is in dit stuk een ietsje minder sterk voelbaar, maar veel maakt dit niet uit.

Het dialect van de fragmenten kan dus nog iets specifieker als vermoedelijk Zuidwest-Vlaams bestempeld worden.

Hoewel op dialectgeografische gronden het handschrift iets jonger lijkt, is er vanuit de paleografische aspecten voldoende aanleiding om het nog in de vroege veertiende eeuw te plaatsen. Daarmee behoren de fragmenten tot de oudste Rijmbijbel-handschriften, zeker als men bedenkt dat het genoemde Brusselse handschrift op het einde van de dertiende eeuw geplaatst moet worden. Hoewel het afschrift van de fragmenten tekstueel zeker niet vlekkeloos genoemd mag worden, is het niet enkel vanwege de ouderdom van belang. Het blijkt namelijk vele lezingen gemeen te hebben met het Brusselse handschrift (bij David handschrift C). Daarmee lijkt de Brusselse codex voor een eventuele toekomstige kritische editie eveneens een goede keuze te zijn. Vanwege hun ouderdom en tekstkritisch belang worden de fragmenten hieronder integraal diplomatisch uitgegeven.

\section{Uitgave van de fragmenten}

Alleen het fragment-Bösensell is bewaard gebleven; van het fragment-Gaesdonck beschikken we nog over een foto van de rectozijde van een van de beide fragmenten, alsmede een volledig afschrift door K. Christ. Het fragment-Münster is integraal beschikbaar in een uitgave door Van Vloten; voorts zijn er gedeeltelijke transcripties van de hand van W. de Vreese en een door zijn vrouw afgeschreven kopie die in de map 'Münster UB' van de BNM bewaard worden. Daarin zijn alle afkortingen opgelost maar niet gemarkeerd; de uitgave-Van Vloten bevat typografische equivalenten van de middeleeuwse afkortingstekens, en ook Christ neemt de afkortingstekens over.

In het algemeen gelden bij de uitgave van de fragmenten de volgende principes: de uitgave is diplomatisch, met dien verstande dat de afkortingen worden opgelost en cursief gezet. Hetgeen in het fragment-Bösensell door ons is aangevuld staat tussen rechte haken. Onzekere lezingen zijn tussen ronde haken geplaatst. Hetgeen niet leesbaar is, wordt door punten weergegeven; het aantal geeft bij benade- 
ring aan hoeveel letters ontbreken. Waar dit onmogelijk is, wordt een streepje tussen ronde haken geplaatst. Romeinse cijfers worden in kleinkapitaal afgedrukt, met weglating van de isoleringspunten. De fragmenten hebben een eigen regelnummering, rechts zijn de versnummers uit de editie-David overgenomen.

De transcriptie van de Gaesdonckse fragmenten door Christ maakt een betrouwbare en degelijke indruk. In het gedeelte dat aan de hand van de foto controleerbaar is komt geen enkele fout voor. Zijn afschrift van de overige delen nemen we integraal over; als er twijfel is aan een lezing, wordt dat in een voetnoot gemeld. De kleine aanvullingen die Christ heeft gedaan, zijn gehandhaafd en tussen rechte haken gezet; de gedeeltes die hij niet kon lezen, hebben we weergegeven met een streepje tussen rechte haken. ${ }^{(26)}$

Over de uitgave-Van Vloten merkt De Vreese in de Bouwstoffen zuinigjes op: 'Het destijds aan J. van Vloten verstrekte afschrift is niet vrij van fouten'. ${ }^{(27)}$ Als we echter de afschriften door De Vreese en zijn vrouw bezien, blijkt dat nogal mee te vallen, sterker nog: sommige lezingen in de uitgave-Van Vloten lijken preferabel. ${ }^{(28)}$ Het probleem in deze editie is evenwel, dat Van Vloten (gedeelten van) woorden en zelfs complete verzen heeft toegevoegd, die meestal tussen ronde haken worden gezet, maar ook wel in cursief. Dit doet zich met name voor aan het begin en eind van een blad, doch het komt ook elders voor. Aan de hand van het gedeeltelijk afschrift van De Vreese, die van elke kolom de begin- en eindregels noteerde, valt enigermate na te gaan wat door Van Vloten werd aangevuld. Hierbij hielp ons ook het gedeeltelijke afschrift door mw. De Vreese (men heeft evenwel de indruk dat Suchier hier en daar meer kon lezen). Hetgeen bij Van Vloten tussen ronde haken staat, is door ons tussen rechte haken gezet; hetgeen bij hem in cursief staat, hebben wij tussen accolades geplaatst. Indien de transcripties uit de BNM van de editie-Van Vloten afwijken, is dit in voetnoot weergegeven. ${ }^{(29)}$

(26) De verwarrende nummering van de fragmenten door Christ hebben wij niet overgenomen.

(27) Zie noot 18 .

(28) Dat verbaast ook niet, want de romanist Hermann Suchier (1848-1914), die de transcriptie aan Van Vloten zond, heeft vele tekstedities van met name Oud-Franse teksten op zijn naam staan, waarvan vele (zelfs postuum nog) herdrukt werden.

(29) Mevrouw De Vreese geeft in haar transcriptie aan dat de fragmenten de nummers 48 en 49 dragen; deze nummering hebben we in onze uitgave niet overgenomen. 


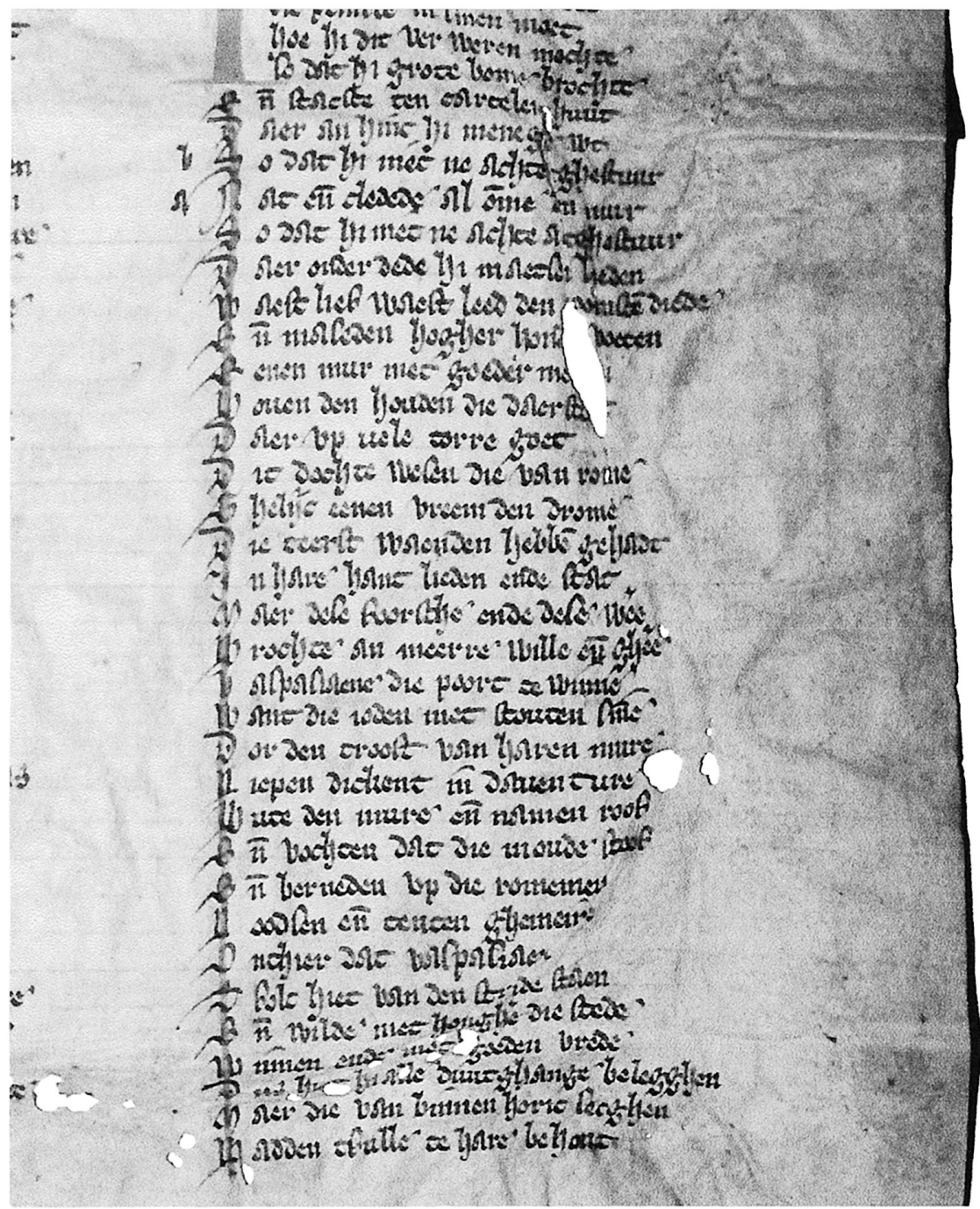

Afb.: Fragment uit de band van Hs. von und zur Mühlen'sche Bibliothek Nünning, Haus Alvinghof, Senden-Bösensell, 20 (detail rectozijde, ware grootte) (C) von und zur Mühlen'sche Bibliothek Nünning) 


\section{Fragmenten GAESDONCK (GA)}

$\mathrm{Ra} \quad 1 \quad$ In dat lant van israel

8245

Dat dese sake al dus geuel

Die myca maecte af gode

$4 \quad$ Van seluere iegen gods gebode

Ende maechde eene $n$ outaer mede

In sijn huus daer hise in dede

8250

Sinen sone hi rente gaf

8 So dat hire pape was af Elc man dede in dien tiden

Dat hi wilde ende liet liden

Vant ${ }^{(30)}$ dat lant was onberecht

8255

12 Myca maecte sinen cnect

Sinen sone pape van hem

Tien tiden was van bellem ${ }^{(31)}$

Een iongelinc van leuijs geslachte

16 Die sine auonture wachte

8260

Waer hi hem generen mochte

So dat hi mycase versochte

$(-)$

[zeven regels weggesneden]

[8263-70]

Dans gheslachte maer si sochten

28 Waer si hem generen mochten

Si sendden spierers alte hant

Om te vindene eenech lant

Te mycase quamen die boden

8275

32 Ende daer sagen si die afgoden

Ende hoet daer ghescepen es

Daer na gingen si in laces

Doe si sagen lant ende stede

36 Ende tfolc sonder soorge mede

Ende dat si niet ne consten striden

Keerden si weder in corten tiden

Ende seident hare $n$ broeders toe $e^{(32)}$

40 Gawi ets best dat ment doe

Wi sullen winnen alte hant

Sonder pine een edel lant

Daer gingen och $\mathrm{VII}^{\mathrm{C}}$ man

(30) Lees Want.

(31) Lees bethleem.

(32) Christ leest hier doe. 
44 Te mycase so quamen si an

Dat si sine afgode doe namen

$\mathrm{Rb} \quad 1$ Ende datter toe be hoorde te samen

8290

Mycas en const weren niet

Die pape volgede dat diet

4 Dien daed si met hem lieden gaen

Ende seiden et es wel ghedaen

Pape te sine van eenen gheslachte

8295

Dan in een huus van cleenre machte

8 Mycase dreeghden si van den liue

Si gingen met kinde ende met wiue

Met beesten ende met haren goede

Ende vinden laces sonder hoede

8300

12 Tfolc slougen si al dooet

Ende braken die steede groot

Daer bi den beerghe lybanus

Maecten si dat seid men hus

16 Eene stat die dan gheheeten es

Die alre eerst hiet laces

Daer hilden si den af god mycas

$(-)$

[zeven regels weggesneden]

[8308-15]

Over driuen of vaen

$28 \quad \mathbf{T}^{(33)}$ eenen tiden oec also wel

Doe dat lant van israel

Sonder eere was onberecht

Soe gesciede dese istorie echt

8320

32 Een gheboren van leui

Die woende eenen beerghe by

Lach int lant van effraym

Die adde een wijf met hym

36 Ende was van bellem geboren

Die van hem sciet om eenen toren

Ende voer weder tharen vader

Die man voer na doe wart al gader

$40 \quad$ Versoent ende souden keeren

Tote haren lande met heeren

In gabaa quam soe met him

Dat int lant es van beniamin

$44 \quad$ Vp die strate hi bliuen soude

Want hem niemen heerbergen woude

(33) Lombarde van drie regels hoog. 
Va 1 [So] dat al daer quam te him

[E]en hout man van effraim

[Di]e sonder magen was int lant

4 [Ende] ontfincse daer te hant

[Nav]ons doe die gone haten

[Q]uam dat bose volc vp die strate

8340

$[\mathrm{E}] \mathrm{nde}$ seiden gef ons den vreemden man

8 [O]nsen wille d[aer ${ }^{(34)}$ mede te doene dan

$[D]$ at was sonder $\mathrm{t}[\mathrm{i}]$ eghen nature

[D]oe leedde (-)

[De]s gast wijf daer si mede daden

12 [Ha]ren wille sonder ghenaden

[Ende] niet ${ }^{(35)}$ als men der redenen pliet

[Ma]er dat die nature weder biet

[Doe]t dach was liet sise gaen

16 [Ende] soe bleef doet sonder waen

[Als] si quamen voor smans duere

[zeven regels weggesneden]

[8352-58]

[M]et tien gingen (-)

[D] at was een haer hoeft stat

8360

$(-)$ hondert te zamen

28 (-) gemeenlijc quamen

[E]nde seiden dat niemen thuus ne ga

[E] er ment wreect vp galbaa

[S]i sendden boden die dus baden

$32[\mathrm{G}] \mathrm{hef}$ ons die dit quaet daden

[W]i wreken dat hier es ghesciet

[S] seiden $\mathrm{wi}^{(36)}$ en doens niet

[O]ec so seid si daer nae

$36 \quad[\mathrm{I}] \mathrm{n}$ die pooert van gabaa

[L]iede $n$ uter poort van beniamin

[Q]uamer XV dusent daer in

[T]e hulpen iegen die onurede

$40 \quad$ [I]n gabaa so waren oec mede

[VII] hondert man harde snel

[M]et beiden handen harde wel

$\mathrm{Vb} \quad 1 \quad \mathrm{Si}$ consten slingeren al gemene

Met beeden handen also wel stene

Dat si geraecten wel een aer

\footnotetext{
(34) Christ heeft dei(..).

(35) Christ heeft hier met.

(36) Christ heeft $W i$.
} 
$4 \quad$ Nv voer alt heere naer

Ter tabernacle in cylo

Ende vrageden onsen heere doe

Wie haer prinsce soude met him

8 Wesen daer iegen beniamin

Ende god seide iudas gheslachte

8385

Doe gingen si vechten met crachte

$\mathrm{Vp}$ gabaa die ten eersten dage

$12 \quad \mathrm{Vp}$ hem daden gro[te] plagen

Want se vp hem slougen dan

Twintich dusent bitender man

Sander dagen dages [ver]loren si mede

16 Hachtien dusent volcs ter stede

Des derds dages met ere lage

Was tfolc van (-)

[zeven regels weggesneden]

[8395-401]

Van beniamin [die] serich bleuen

Vier maent achter een

28 Dreuen harde groten ween

Tfolc van israel weet dat

Ghebood in die poert van massat

Dat niemen doe van beniamin

32 Sijn kint ne gaue van him

Doch dat hem berou die tale

Dat een gheslachte alte male

Ghebreken soude van israel

36 Doe besocht sijt harde wel

Dat die van gapis ende van galaat

Hem niet en holpen tiegen die stat

Dat folc slougen si groet ende cleine

8415

40 Sonder $\mathrm{IIIJ}^{\mathrm{C}}$ maghede allene

Dien gauen si die van beniamin

Dat belooefden si oec him

FRAGMENTEN MÜNSTER (MÜ)

$\mathrm{Ra} \quad$ [eerste twee regels afgesneden]

[Sie]t mine hande ende mine voeten ${ }^{(37)}$

[26907-8]

$4 \quad$ [Ende be]tasse met goeder moeten ${ }^{(38)}$

26910

[Die] geest ne heuet vleesch no been

(37) Bij De Vreese begint bij dit vers Ic.

(38) De Vreese leest: (...)t alle met goeder moeden. 
[Dat] ghi siet ane mi ghemeen

[Doe] toghede hi hem ten seluen stonden

8

[Lijct]ekene van elker wonden

[An] handen an voeten ende in siden

[Vanden $\left.{ }^{(39)}\right]$ wondre worden sy so blide

[Noc]htan ne gheloueden sijt niet

12 [Ihesus $\left.{ }^{(40)}\right]$ seide hebdi hiet

[Dat] men mach eeten aldaer ten dichsce

[Bro]chtemen hem van gebradene vissche

[Ende] daer toe honechraten mede

16 Hi at daer vor hem ter stede

[Ende] sijn relief gaf hi hem vord

[Doe] seide hi dit sijn die word

[Die] ghi vernaemt van my

20 [Doe] ic steervelic was alse ghi

[Hie]n dede hem den syn

[Dat] si verstaen mochten daerin

[Die] scrifture ende sprac na desen

24 [Ghi] sult mine orconde wesen

[Van] \{desen $\}$ dinghen tallen den lieden

[Ende] begonde dit bedieden ${ }^{(41)}$

[Alh]ier van iherusalem ${ }^{(42)}$

28 [Vro] $\left\{\right.$ waren sy onder hem alle ${ }^{(43)}$

[Dat] sine bekenden in ${ }^{(44)}$ desen

[Si]et pays \{moete met $\mathrm{v}$ wesen

[Doe] hi adde ghewagen dies

32 [Up] sine ionghers dat hi blies

[Ende] seide alse wijt hebben verheest

[Nee]mt al hier den helegen geest

[Die]n ghi verlaet sine sonden

36 [Ver]laten bliuen si tallen stonden

[Ende] dien ghi bint bliuet gebonden

[Des]e bande van deser orconde

[He]vet die paues ende van hem mede

(39) Oplossing van Van met streepje boven de $n$.

(40) Bij Van Vloten ih met superscripte $s$.

(41) Van Vloten heeft bedieten.

(42) Einde Ic.

(43) Bij De Vreese begint hier IIc. In zijn gedeeltelijke transcriptie is deze regel met punten weergegeven.

(44) De Vreese leest maer. 
40 [Die] papen van karstineden

[Al]dus leest men dat menne sach

[Vi]if warfven vp den paschedach

[Die]s keert hem omme ${ }^{(45)}$ weet vorwaer

44 Die pape vijf warf in den outaer

$\mathbf{M}^{(46)}$ ettien als hi ontvaren was

So quam weder in thomas

[En]de die ionghers dies gewaghen

$\mathrm{Rb} \quad 1 \quad$ [Datsi onsen here daer saghen ${ }^{(47)}$

[Thomas diene gheloves niet]

Hi seide hen sy dat hi siet ${ }^{(48)}$

$4 \quad$ Handen ende voeten geslegen dure

Ende tgat in die syde ter cuere

Ende hire sinen vingher in steke

Hine ghelovets niet zekerleke

8 Ouer vill daghe daer na geuel

Dat die ionghers also wel

Vergadert waren ende thomas

In den huse mede was

12 Onder hem beslotenen dueren

Quam Ihesus $^{(49)}$ ter seluer hueren

Doe seidi met hu sy vrede

Daerna seide hi thomase mede

16 Bring hareward den vingher dijn

Sie die handen ende die siden mijn

Ende wes niet ongelouich meere

Maer ghetrouwich doe seidi heere

20 Mijn god ende mijn heere mede

Ihesus seide daer ter stede

Want du hebs gesien thomas

Bedy so gelovestu das

24 Salich sijn sy diet noyt sagen

Ende geloven dies mach behagen

Ons ${ }^{(50)}$ allen die daer na sijn comen

Dit ende meer tonser vromen

(45) Afk. ome met streepje boven de $m$.

(46) Lombarde, bij Van Vloten twee regels hoog.

(47) Deze en de volgende regel (vs. 26954-5) zijn in werkelijkheid weggesneden.

(48) Bij De Vreese begint bij dit vers Id. Hij heeft liet i.p.v. siet.

(49) Van Vloten heeft $I h^{\prime} c$.

(50) De Vreese leest Dus. 
28 [Dede Jhesus dat noch es bleven] ${ }^{(51)}$

In die ewangelie onbescreuen ${ }^{(52)}$

$\mathbf{D}^{(53)}$ aer na [openbaerde] h[em] mee

Ihesus ${ }^{(54)}$ ten mere van galilee

32 Dit was die darde dach te waren

Daer hi hem vp wilde openbaren

VII ionghers visscheden daer

Om hare lijfnere dat es waer

36 Bin al der nacht sone vingen sy niet

Als men dien dach scone siet

Stont vpten ${ }^{(55)}$ ouver ihesus

Ende seide te hem al dus

$40 \quad$ Werpt an die rechter zide $\mathrm{v}^{(56)}$ net

So suldi visschen te bet

Doe si dat hadden ghedaen

Waest vul groter visschen zaen

$44 \quad \mathrm{C}$ ende $\mathrm{L}$ ende drie

Ian seide dat lesen wie ${ }^{(57)}$

Dat het onse heere ware

Alse pieter hoorde die mare ${ }^{(58)}$

Va 1 [Dat Ihesus was nam hi sinen roc $]^{(59)}$

[Want hi was naect ende sonder stoc]

Mae $[\mathrm{de}]^{(60)}$ hi hem te lande waert ${ }^{(61)}$

4 Alse diene zere te siene begart

Een scotmael ${ }^{(62)}$ waest wel van den lande

Die andre roerden hare hande

Ende quamen metten scepe naer

(51) Van deze regel lijkt niets (meer) te zien te zijn.

(52) Bij De Vreese begint met deze regel IId. Van mw. De Vreese is een kopie van de resterende 18 regels van de kolom; van de eerste regel (vs. 26983) geeft haar afschrift alleen de lombarde $D$, van de volgende regel (vs. 26984) niets.

(53) Lombarde, hoogte niet bekend.

(54) Van Vloten heeft $I h$ 'c.

(55) Mw. de Vreese heeft upten.

(56) Mw. de Vreese heeft $u$.

(57) In de kopie van mw. De Vreese staat tussen seide en dat een punt.

(58) Einde IId.

(59) Deze en de volgende regel (vs. 27001-2) zijn in het handschrift weggesneden.

(60) Lees maecte.

(61) Bij De Vreese begint bij deze regel Ia. Hij kan het betreffende vers niet (helemaal) lezen en plaatst daarom een aantal punten. De kopie van mw. De Vreese bevat de regels 427.

(62) De Vreese heeft stotmael, zijn vrouw stocmael. 
8 Doe si te lande quamen daer

Vonsi vier te harer noot

Ende visschen daer $\mathrm{vp}^{(63)}$ ghereet ende broot

27010

Doe ${ }^{(64)}$ brieden si van den visschen mede

12 Die si vinghen daer ter steede

Ende ghinghen met ihesus ${ }^{(65)}$ eeten

Alse die wel die wareit weten

Dat het onse heere sy

27015

16 Pieter die hem daer sat by

Vraghede drie waerf onsen heere

Of hine int herte minde zeere

Dan hiemen die ginder sat

20 Pieter keerde an gode dat

Ende seide du weets dat wel

Aldaer hem onse heere beuel

Dat hi sine scaep soude voeden

$24\{$ leeren\} wisen ende hoeden

Doe vorseide hi hem na desen

27025

Dat hi ghecruust soude wesen

Ende hiet hem dat hi hem uolgede mede ${ }^{(66)}$

28 [Ende sterve] \{ant cruce a(lshi dede)\}

$\mathbf{O}^{(67)}$ nse heere ghinc dane ${ }^{(68)}$

\{Ende pieter uolgedem ane ${ }^{(69)}$

Als die wel waent doen daeran

32 Daer na uolghede hem ian

Pieter sach omme mettien

Ende heuet hem uolghende versien

Here seit hi wat van desen

27035

36 Hoe saelt met sinen ende wesen

Dat ic ant cruce steeruen moet

Sech wat enden dese doet

Ic wille hi bliue sprac onse heere

(63) Mw. De Vreese heeft up.

(64) Mw. De Vreese heeft Soe.

(65) Van Vloten heeft $i h^{\prime} c$.

(66) Einde Ia.

(67) Lombarde, bij Van Vloten twee regels hoog.

(68) Bij De Vreese begint met deze regel IIa. Het afschrift van zijn vrouw omvat deze en de volgende 18 regels (vs. 27029-47).

(69) De Vreese leest alleen de eerste twee woorden, zijn vrouw heeft aan het einde van de regel nog ane. 
40 Totien dat ic weder keere

Die ionghers die waenden dan

Om dit woord dat sinte ian

Toten doemsdaghe leven soude

$44 \quad$ Maer ihesus ${ }^{(70)}$ meende dat hi woude

Dat sijn lijf worde ghehend

Sonder martelaers torment

Die ionghers daer na alle quamen ${ }^{(71)}$

$\mathrm{Vb} \quad 1 \quad$ [In t lant van galylee te samen] ${ }^{(72)}$

[Up enen berch daert god gheboot]

Daer saghen sy ihesus ${ }^{(73)}$ den heere $\operatorname{grot}^{(74)}$

$4 \quad$ Si anebeedene ${ }^{(75)}$ te harer vromen

Nochtan twifelde hem somen

Onse heere lachterde hem daer ter stede

Harer herten grote aertheede ${ }^{(76)}$

$8 \quad$ Hi sprac mi hes in hemelrike

Ghegeuen ende in aerdrike

Alle macht spreect mine tale

Die werelt dure al te male

12 Leert allen lieden clene ende groot

Te houdene dat ic ghebood

Ende te dopene in die name des vader

Ende tsoens ende shelichs geests te gader

16 Die ghelooft ende menne doopt in desen

Dieghone sal behouden wesen

Die niet ghelouet bliuet verloren

Miracle seidi hem te uoren

20 Die si souden doen als et quam

Te siere vpuaert als ict vernam

Quam hi te iherusalem

Bliuet in die stat sprac hi te hem

24 Tote dien dat ghi den helegen geest ontfaet

Mettien hi met hem eeten gaet

Daer na leedise vter stede

Te mont oliueten mede $\mathrm{e}^{(77)}$

\footnotetext{
(70) De Vreese heeft Ih'c.

(71) Einde IIa.

(72) Deze en de volgende regel (vs. 27048-9) zijn in het handschrift weggesneden.

(73) Van Vloten heeft $I h ' c$.

(74) Bij De Vreese begint bij deze regel Ib.

(75) De Vreese heeft ane beedene.

(76) Van Vloten heeft ae'theede.

(77) Einde Ib
} 
$28\{\text { Sine handen heuet hi vp geheuen }\}^{(78)}$

Ende hem benedixie ghegheuen

\{Doe word hi vpgheheuen\} saen

Een claer zwerc heeftene ontfaen

32 Daer hem dinghel mede dienden

Doe hi sinen lieuen vrienden

Onthoghet was sagen sy nochtan

Vpwaerd na den lieuen man

27082

36 Dit was asensyoens daghe ${ }^{(79)}$

Dat hi vp voer sonder zaghe

Mettien quamen bi hem staen

Twe ingle als man ghedaen

40 Die seiden manne van galylee

Wat siedi vp te hemele mee

Hi sal noch weder comen te waren

Also als ghine vp saghet varen

$44 \quad$ Si keerden in iherusalem

Ende waren in bedinghen tote dat hem

27090

Die helighe gheest daer was gesent

Daer na gingen sy omtrent $t^{(80)}$

\section{FRAGMENT BöSENSELl (Bö)}

Ra 1 Daer ieghen dat was vast die stede

Begonste hi den muer bestaen

Iosephus wort veruaert saen

$4 \quad$ Ende met hem alle die ioden mede

Te verliesene die stede

Die porten hedsy ${ }^{(81)}$ vp ghedaen

Ende die [ro]meine so bestaen

8 Dat [sy] met groter manlicheden

Wonder (d)aden b(vt)er stede

Want ghelijc dat van wanhopen

Die ioden worden staerc ende stout

(78) Bij De Vreese begint met deze regel IIb. Hij kan van het vers niets meer lezen en plaatst een aantal punten.

(79) Deze en de volgende regel komen niet in de uitgave-David voor, ook niet onder de variante lezingen.

(80) Einde IIb.

(81) Zal een verschrijving van hebsy zijn, aangezien in het Vlaams een vorm met umlaut uitgesloten is (mededeling prof. Berteloot). 
12 Ghelijcker wijs so worden bout

Die romeine van scamelheden

Dus street men sere buter steden

Maere die romeine streden

16 Bede met crachte ende met wijsheden

Ende die ioden met grammen ${ }^{(82)}$ moede

Ghelijc dat uechten die verwoede

So dat men dien dach dore uacht

20 Ende den strijt versciet d(i)[e]n nacht

Der romeine ware ${ }^{(83)}$ uel[e] gewont

XIII bleuer doot daer ti[e]r stont

Ende van den Ioden $\mathrm{x}$ ende VII

24 Gherouet van haren leuene

$\mathbf{T}^{(84)}$ en darden daghe daer na camen

Echt die romeine te samen

Ende die ioden camen ter were

28 Ander werfuen ieghen theere

Men streed vijf daghe andie mure

Maer die scaemte maecte stuere

Die romeine vp die van binnen

32 Doch ne wasser an gheen winnen

Want die ioden ont saghen niet

$\mathrm{Al}$ die crach ende alt verdriet

Dat die romeinen gheleesten mochten

36 Ende die romeinen die sere vochten

Ne wilden omme doot no om leuen

Dat assaut ooc niet begheuen

Al was die stat vast ende goet

40 Van Iotapata dat stoet

Wel na(er) vp die rootsche al

Daert onder was so diep een dal

Dat niemen neder waerd dat gras

44 Ghesien ne mochter watter onder was

Allene andie side noord

Mochtmen ghenaken der poord

[Al d]aer die beerch enden beghan

48 [Dae]r Iosephus die vroede ${ }^{(85)}$ man

Hadde gedaen maken sulke mure

$[\mathrm{N}] \mathrm{e}$ hadde ghedaen die auenture

(82) Afkortingsstreepje staat boven de $m$ van gramen.

(83) Afkorting w'e.

(84) Rode lombarde, vier regels hoog.

(85) $v$ gecorrigeerd uit $b$. 
Die men winnen niet ne mochte

$52 \quad$ Al ward dat menre heere ${ }^{(86)}$ toe brochte

Vaspasiaen die sach die ste dede

So uast by nature[n] mede

28580

$\mathrm{Rb} 1$ Ende die ioden stout ende starc

Die sine riep hi in een parc

Ende hiet dat sy droughen dracht

4 Ende wulden die gracht

Daer toe haeldemen hout ende stene

28585

Ende alt volc dat drouch gemene

Ver dect met taersen ende met scilden

8 Maer die de stat van binnen hilden

Scoten ende worpen stenen

Ende worpen vier ghemene

28590

Daer sy die tarsen ende die dracht

12 Ver berneden die lach in die gracht

Nochtanne word an haren danc

Die gracht veruullet eer hiet lanc

Ende enen dijc so hoghe ghedragen

28595

16 Ende daer up eenen hoghen mur daer in laghen

Scotters die die van der stede

Quedsten ende wonde mede

$\mathbf{I}^{(87)}$ osephus die sere was vroet

20 Die peinsde in sinen moet

Hoe hi dit ver weren mochte

So dat hi grote bome brochte

Ende stacs[d]e ten cartelen huut

24 Daer an hinc hi menege wt

b So dat hi niet ne achte ghestuur

a Nat ende cledede al omme [d]en mur

So dat hi niet ne achte a[1] tghestuur

28 Daer onder dede hi maetse[n] lieden

Waest lief waest leed den [r]oomscen diede

Ende maleden hogher hond[ert] voeten

Eenen mur met goeder mo[ete]n

32 Bouen den houden die daer st[oe]t

Daer vp uele torre goet

Dit dochte wesen die van rome

Ghelijc eenen vreem den drome

(86) Afk. h'ee.

(87) Rode lombarde, vier regels hoog. 
36 Die teerst waenden hebben gehadt

In hare hant lieden ende stat

Maer dese foorsche ende dese weere ${ }^{(88)}$

Brochte an meerre wille ende gheere ${ }^{(89)}$

$40 \quad$ Vaspasiaene die poort te winne

Want die ioden met stouten sinne

Dor den troost van haren mure

Liepen dickent in dauenture

44 Bute den mure ende namen roof

Ende vochten dat die moude stoof

Ende berneden vp die romeinen

Loodsen ende tenten ghemeine

48 Onthier dat vaspasiaen

Tfolc hiet van den stride staen

Ende wilde met honghere die stede

Winnen ende met goeden vrede

28630

52 Dus hiet hi alle duutghange belegghen

Maer die van binnen horic secghen

Hadden tfulle te hare behout

Va 1 Maer dat hem ghebrac sout

Ende waters had sy cleine

Want daer ne was ghene fonteine

$4 \quad$ Mar reinene water hadsy in pitten

Doch te somere in der hitten

Alst doe was als mense belach

Reynet daer ${ }^{(90)}$ selden nacht of dach

28640

8 Iosephus dede by mesuren

Water gh[eue]n d[en] gh[ebur]en

So dat (die) [ro]meinen [ver]na(men)

Ende waen(den) wel d(i -)

12 Hebben saen in hare (-)

28645

Doe dat iosephus beuant

Hinc hi natte cledre wt

Ten mure ende stelpede dat gel[uu]t

16 In dier ghelike In dier geba(r)e

Als offer waters te clatte ware

Alse dit die rome[ine] saghen

Begonste hem sware d(i.. be)hagen

20

$\mathbf{U}^{(91)}$ aspasiaen die wart belopen

(88) Afk. w'ee.

(89) Afk. gh'ee.

(90) Interliniair toegevoegd.

(91) Rode lombarde, drie regels hoog. 
Om dese dinc in wanhopen

Dat hi niet ne w(o)[nn]e die stede

28655

Met darste no met honghere mede

24 Ende wart te rade dat hise saen

Met wapenen wilde [b]estaen

Dit was dat die [i]oden begaerden

Want sy saghen $h($ ar)er vaerden

28660

28 Mocht sy niet vlie[n] vten onurede

Noch ver weren (oe)[c] die stede

Dies hadsi l(-) den strijt

Te steeruene in [co]rter tijt

32 Dan van hongh[e]re ofte van darste

28665

Te doghene smartelike barste

Iosephus vant (oo)c andren raet

Nadien da(t) hem dus sware staet

36 Dor een onbekenlic dal

Daert ongheweeght was al

28670

Sendy boden die in die stede

Brochten alle bedurste mede

$40 \quad$ Hi hiet alsi ten wachters camen

Dat sy (r)uwe uel an namen

Ende oue[r] ha[n]de ende ouer voete gaen

28675

So waren sy alle als hond(e) gedaen

44 Van derre lust [qu]am hem groet goet

Onthier dat (th)ere verstoet

Ende beleiden hem so ( $\mathrm{t}$ )dal

Dat he $(t)$ [was] b(e)[1]eghen al

$48 \quad \mathbf{D}^{(92)}$ oe v[ern]am wel iosephus

28680

Als hi belegen was aldus

Dat $\mathrm{m}(\mathrm{e} n)$ [niet] lange [van] danen vord

Houden moch[te] ghone poort

52 (Ende) adde sijns leuens vaer

W(-) (da)t hy bleue daer

$\mathrm{Vb} \quad 1$ So dat hy metten besten raet

Nam (t)ont vliene na dat staet

Maer die meente words geware

$4 \quad$ Ende camen om hem (..)re scare

Ende baden dat hise ni[et en] liete

Want hi was van haren verdriete

Troostere ende hulpe allene

(92) Rode lombarde, drie regels hoog. 
8 Sy wilden gherne alle ghemene

Vor hem steruen hi ware har here

Ende u(lo hi ooc) he(m) (-) (e)re

Van s(inen) vrien[den] (-)

12 Iosephus deckte sine[n] (-)

Ende seget dat hi beghart die vl[u]cht

Om den romeinen te doene (vrucht)

28700

Hine mach binnen niet uele (-)

16 Ende comt hi buten hi sal poghen

Den romeinen te doene wee

Hi sal achter galylee

Here gadren ende met stride

28705

20 Die stat ontsetten in corten tyden

Ende daer inne vromt hi hem niet

Sonder dat dat roomsche diet

Omme dat menne daer inne weet

$24 \quad$ Vp die port strijt al gereet

28710

$\mathrm{Die}^{(93)}$ meenthucht ne achte alte male

Clene no groot dese tale

Kinder wijf groot ende clene

28 Camen wenende al ghemene

Tsinen voeten ende baden

Dat hise ne liete niet verladen

Ende hi hem niet ne wilde ont(s)[ien]

32 Hem ne mochte niet messchien

Also lange als hi met hem ware

So dat hi al open ba[re]

Seide hi wilde met hem bliuen

36 Ende hem al daer (la)[ten] on(tliu)en

Ende hem cam in sinen moet

Wan hope als een die was verwoet

Ende seide vriende nu est tijt

40 Dat men ane ua den strijt

Hier es geen ontgaen wie sooet becrone

$\mathrm{Bi}$ gode hets eerlijc ende scone

(D)a[t men] gheue tlijf dor die eere

44 M[en best] (a die) [vi](ande) so seere

(Ende) [men] doe (so) grote $(n)$ mort

Dat men (t)elle emmer meer voort

Dit sprac hi ende heuet bestaen

(93) Links van de regel lijkt met zwarte inkt een paragraaftekentje te zijn geplaatst. 
48 Mett(en) besten den wijch saen

Wter stede(n) es hi gestreken

Ende ghinc h(a...) lijtschen breken

Ia [toten r]oomschen pawelioenen

52 Ghinghen si ghelij[c] den lyoenen

Hare engiene hi ende (-) 